\title{
Positional preferences and efficient capital accumulation when households exhibit a preference for wealth
}

\author{
By Sugata Ghosh ${ }^{\mathrm{a}}$ and Ronald Wendner ${ }^{\mathrm{b}}$
}

a Department of Economics and Finance, Brunel University London, Uxbridge, UB8 3PH; e-mail: sugata.ghosh@brunel.ac.uk

b Weatherhead Center for International Affairs, Harvard University, Cambridge, MA 02138, USA, and Department of Economics, University of Graz; e-mail: ronald_wendner@ fas.harvard.edu;

ronald.wendner@uni-graz.at

\begin{abstract}
We study the impact of positional preferences - with respect to wealth in addition to consumption - on endogenous growth, welfare, and corrective taxation. We consider first an AK model, and then introduce public capital. Labor supply is exogenous. We find analytically that the presence of wealth positionality always causes distortions (although a preference for absolute wealth by itself is non-distortionary). Consumption positionality introduces a distortion only if wealth is an argument in the utility function and the marginal degree of positionality in wealth does not match that of consumption. Two corrective tax instruments: a consumption- or an income tax, are required for internalization of externalities in an AK set-up; the optimal choice of public investment is an additional instrument when public capital is introduced. Numerical simulations - pointing towards high corrective tax rates and their strong impact on growth and welfare - complement the theoretical analysis.
\end{abstract}

JEL Classification Numbers: D62, H21, O41 
The poor man's son ... when he begins to look around him, admires the condition of the rich. ... He does not even imagine that they are really happier than other people: but he imagines that they possess more means of happiness. ... And it is well that nature imposes upon us in this manner. It is this deception which rouses and keeps in continual motion the industry of mankind. It is this which first prompted them to ... build houses, to found cities and commonwealths, and to invent and improve all the sciences and arts, which ennoble and embellish human life; which have entirely changed the whole face of the globe. (Smith 1759, 1976, IV.vii.1.8-10)

\section{Introduction}

As the above passage from his Theory of Moral Sentiments highlights, social comparisons and conspicuous consumption were considered significant attributes by Adam Smith, writing in the mid-eighteenth century. Likewise, in his Theory of the Leisure Class, Thorstein Veblen (1899) emphasized the quest for status - via conspicuous consumption and wealth - as an important component of the pursuit of self-interest. ${ }^{1}$ Aside from classical economists and political philosophers such as Smith and Veblen, among others, positional (or referencedependent) preferences, ${ }^{2}$ where the reference point is social distinction and/or status in relation to others in society, were studied from ancient times by philosophers like Plato, and so have a very long history.

Given the importance of positional preferences, as echoed by Smith and others of repute, this paper studies the impact of such externalities on endogenous growth, welfare, and corrective taxation - when people are positional with respect to wealth in addition to consumption. In contrast to the previous literature, we show that the presence of positionality in wealth always introduces a distortion (irrespective of whether consumption positionality exists), which is corrected by an optimal consumption- (income-) tax that is negative (positive). Also, positionality with respect to consumption is almost always distortionary, and this is despite the fact that labor supply is exogenous, so long as individuals either have a preference for wealth or are positional with respect to wealth. This is because the Keynes-Ramsey rule differs between the decentralized economy and the social optimum in that case, as the marginal utility of wealth then depends on the consumption externality.

\footnotetext{
${ }^{1}$ Veblen, thus, argues: "Conspicuous consumption of valuable goods is a means of reputability to the gentleman of leisure." (Veblen, 1899, p. 64).

${ }^{2}$ Different terms for positional preferences have been used in the literature, with slightly differing meanings. They include status preferences, status consumption, conspicuous consumption, conspicuous wealth, relative consumption, relative wealth, keeping up/catching up with the Joneses, jealousy/envy, external habits, or simply consumption externality.
} 
Positional preferences expressed through social comparisons, from an individual standpoint, are highly topical today as well. One can consider a thought experiment where one is asked to choose between world $\mathrm{A}$ in which they will live in a 4,000-square-foot house and others will live in 6,000-square-foot houses; and world B, in which they will live in a 3,000-square-foot house, others in 2,000-square-foot houses. If only absolute consumption mattered, A would be clearly better. Yet most people say they would pick B, where their absolute house size is smaller but their relative house size is larger. ${ }^{3}$ This issue about positionality could be quite important from a national perspective as well. A nation builds up its stocks of weapons to match those of rival nations in a scenario where estimates of a rival's arms stocks are imperfect, and thereby spending on arms in equilibrium typically turns out to be more than is warranted. As pointed out by Frank (2008), cross-national comparisons for armaments are more pronounced than for other consumption goods, as consequences of being less armed than others (and thereby compromising on national security) are more severe than for other consumption goods.

In the more recent past, positional preferences have been studied extensively, and their high empirical significance has been well established (cf. Solnick and Hemenway (1998), (2005), Johansson-Stenman et al. (2002), Alpizar et al. (2005), etc.). These papers find hard evidence for strong positional concerns over income: people are willing to forsake higher absolute income but lower income relative to others in favor of lower absolute income but higher relative income. For example, Alpizar et al. (2005) and Solnick and Hemenway (2005) find that people are positional regarding durable goods like houses and cars (certainly more than for leisure time like vacations). ${ }^{4}$ These results also strike a chord with the happiness literature, following Easterlin (1995), where positional preferences help to explain the Easterlin paradox, which shows that while US real income per capita almost doubled over the period, 1973-2004, happiness levels have remained static. This is largely because for most people, income is a positional good, and as such they prefer to have more income than others in their reference group (which is less true about leisure).

\footnotetext{
${ }^{3}$ See Frank $(2005,2008)$, who uses the term positional good to denote goods for which the link between context and evaluation is strongest.

${ }^{4}$ For a recent review of the literature, see Truyts (2010), Eckerstorfer and Wendner (2013), or Wendner (2014).
} 
In this context, the issue of whether and how public policy should be geared towards addressing the "inefficiency" associated with positional preferences becomes moot. ${ }^{5}$ Within the literature on optimal income taxation, it has been shown that with social comparisons being present, substantially higher optimal marginal income tax rates may result; see Oswald (1983), Blomquist (1993), Ireland (2001), Aronsson and Johansson-Stenman (2008, 2010, 2013), Wendner and Goulder (2008). Frank (2005) and Layard (2006), among others, advocate taxation on income or consumption in order to correct the inefficient misallocation of time whereby people spend too much time working to achieve what is at best a temporary gain in relative income. In Alonso-Carrera et al. (2005), a consumption externality makes the decentralized equilibrium allocation inefficient, which can be corrected by either a consumption tax or an income tax. If consumers' willingness to shift current consumption to the future is sub-optimally low (high), then optimal fiscal policy consists of either a decreasing (an increasing) sequence of consumption taxes or a subsidy (tax) on income/output. In Nakamoto (2009), the reason for the decentralized outcome to differ from the first-best is due to a preference for wealth: when households feel jealousy (admiration) about others' consumption, the long-run levels of consumption and the capital stock are lower (higher) than the social optimum, calling for a positive (negative) consumption tax and a negative (positive) income tax.

A salient feature of our baseline model is that households derive satisfaction from accumulating wealth, and also exhibit positional preferences with respect to wealth. As this is a key contribution of this paper, we introduce positionality with respect to consumption as an extension of the main model. Also, as we seek to identify distortions stemming from externalities in the absence of a work-leisure choice, we consider labor supply as being exogenous. ${ }^{6}$ On the production side, we consider first a simple endogenous growth framework with an $A K$ framework, following Rebelo (1991), and later complement this with public capital as the growth engine, a la Futagami et al. (1993). We devise corrective income- and consumption tax instruments that enable the decentralized economy to achieve the first-best

\footnotetext{
${ }^{5}$ A nice example of such inefficiency is provided by Frank (2008): if some job candidates begin wearing expensive suits for interviews, then from any individual job seeker's point of view, the best response might well be to wear the same; however, this outcome may be inefficient, since when all spend more on such suits, each candidate's probability of success remains unchanged. Here some form of collective restraint on expenditure would be useful, but private negotiations are likely to be impractical and hence public policy could provide a solution.

${ }^{6}$ In sharp contrast to the prior literature (see, for example, Rauscher (1997a), Fisher and Hof (2000), Liu and Turnovsky (2005)), where positional preferences with respect to consumption do not cause any distortions along a balanced growth path so long as labor supply is exogenous, here the fact that individuals derive utility from wealth is sufficient to cause distortions under consumption positionality.
} 
outcome, and proceed to compare decentralized and optimal growth rates and welfare levels in our model.

In this paper, wealth in the form of capital is an argument in households' utility functions, as in Zou (1994, 1995), Corneo and Jeanne (1997), Futagami and Shibata (1998) and Nakamoto (2009), etc. One motivation for the inclusion of capital in utility is due to Zou (1994) following Weber (1904) - who argues that the incentive for accumulating capital lies not only in maximizing long-run consumption, but also to increase wealth, which in itself adds to agents' utility. Wealth-dependent preferences have been considered in the earlier literature as well, primarily focused on the Pigou- (or real balance-) effect. ${ }^{7}$ Later, wealth in the form of real money balances, which provide utility by facilitating transactions and reducing shopping time (see, e.g., Croushore 1993), was introduced directly into the utility function in Ramseytype of optimizing models.

In addition, households are also positional with respect to wealth in our model. In the context of positional preferences, (relative) wealth has been frequently considered an argument in the utility function before (cf., among others, Corneo and Jeanne 1997, 2001, Fisher and Hof 2000, 2005, Futagami and Shibata 1998, Hof and Wirl 2008, Pham 2005, Rauscher 1997a, Tournemaine and Tsoukis 2008). The origins of positionality as regards wealth can be traced back to the concept of 'Protestant ethic', coined by Max Weber (1904), who argued that the rise of capitalism came hand in hand with notions of puritanism/asceticism, thriftiness and piety, which was manifested in the accumulation of wealth and assets, rather than via conspicuous consumption (see also Rae, 1905, pp. 59-60). As Rauscher (1997b) contends, given that such norms are social phenomena, it is not "an absolute measure of asceticism" but "a socially determined standard" that is relevant, and the more puritan/ascetic the average person in society is, the more puritan must the individual person be to satisfy that norm. This notion of status, and the means to attain that, could explain why some countries (for example, in Northern Europe) have typically witnessed higher rates of saving and capital accumulation than some others (in Southern Europe) over the years.

\footnotetext{
7 The idea behind the Pigou effect is that if the economy is stuck in a "liquidity trap" situation with unemployment and falling prices (but an unchanged nominal money stock), then at some point people would start feeling sufficiently wealthier due to the higher real balances at their disposal; this would stimulate aggregate demand via consumption, and thereby overcome the unemployment problem.
} 
With these features, we can now highlight some of the important contributions of our paper. First, with absolute wealth in the utility function, but without positionality in wealth (or consumption), there is no distortion, and hence there is no divergence between the decentralized outcome and the social optimum (first-best). But once people are positional in wealth, individual wealth accumulation introduces an externality, and the presence of absolute wealth does impact on the strength of the distortion via the marginal utility of wealth.

Second, if positionality in wealth is introduced (with or without absolute wealth in utility), it follows from above that there is always a distortion, which requires consumption- or income taxes/subsidies to correct the distortion. In some respects, our paper is close to Nakamoto (2009), where labor supply is inelastic, as in our case. In both set-ups, the distortionary effect of consumption externalities persists in the long-run because of wealth-dependent preferences. The key differences, however, are that our paper is an endogenous growth model while he considers a neoclassical growth model, and also that wealth externalities are not considered by him. It is important to observe that in contrast to our paper and Nakamoto's, in the prior literature that does not consider wealth positionality but considers consumption externalities instead, the latter are distortionary only when leisure is an argument of the utility function. ${ }^{8}$ In the absence of work-leisure choice, a consumption externality does not have any impact on the steady state equilibrium of a decentralized economy. (See, for example, Rauscher (1997a), Fisher and Hof (2000), and Liu and Turnovsky (2005), in the context of a neoclassical growth model). By contrast, in our case it is not elastic labor supply that makes the consumption externality distortionary, but rather the wealth externality that does so, because it impacts on the marginal utility of consumption.

Third, if absolute and relative wealth are both included in the utility function (the baseline case), then a consumption subsidy or an income tax has to be employed to correct the distortion and prevent too much wealth accumulation relative to the social optimum. If, in addition, individuals are positional also with respect to consumption, and providing the desire to raise consumption is different from the desire to increase saving (wealth), the optimal consumption and income tax rates differ from zero even if government spending is chosen optimally. For empirically supported degrees of positionality, these corrective tax rates are typically quite large, and they impose substantive effects on the growth rate and welfare.

\footnotetext{
${ }^{8}$ For instance, in Dupor and Liu (2003), Liu and Turnovsky (2005), and Turnovsky and Monteiro (2007), where labor supply is endogenously determined, the decentralized economy diverges from the social optimum in the long-run.
} 
Hence, our theoretical and numerical results give rise to several policy prescriptions, which critically depend on whether households are more positional with respect to consumption or to wealth.

Fourth, for the special case of the marginal degree of positionality of wealth exactly matching that of consumption, there is no distortion, as the two externalities exactly counteract each other, and hence the optimal consumption- and income taxes/subsidies are both zero. This is in contrast to Nakamoto (2009), where wealth externality is not present.

Fifth, for the earlier case, stronger positional preferences via conspicuous wealth and conspicuous consumption both have a direct and positive impact on the endogenous growth rate, providing the intertemporal elasticity of substitution is less than 1, because then positional preferences raise the (long run) elasticity of intertemporal substitution. In an endogenous growth framework with a simple $A K$ technology like us, Carroll et al. (1997) show that the more individuals care about how consumption compares to the reference level, the higher will be the growth rate of consumption in the steady state. In Futagami and Shibata (1998), if all consumers are identical, the long-run balanced growth rate is positively related to the degree of status preference (but this may not hold with heterogeneous agents). Other papers which consider the impact of reference-dependent consumption on growth include Liu and Turnovsky (2005), where endogenous growth - but not via public capital - is considered, a positive production externality leads to the decentralized growth rate falling short of the socially optimal rate (with inelastic labor). Here, consumption externalities affect the magnitude of the distortion caused by the production externality.

Finally, we employ our framework to analyze three fiscal policy experiments involving an increase in spending on public capital financed by lump-sum, income- or consumption taxes. Our numerical results indicate that public spending positively affects both growth and welfare in the steady state, and does so quite strongly. This effect via the production side clearly dominates the consumption externalities in this regard. The latter is reflected also in the 'decisive' way in which some of the key variables adjust along the transition path in response to the three fiscal shocks. ${ }^{9}$

\footnotetext{
${ }^{9}$ These results are available in the online appendix rather than in the body of the paper due to space considerations.
} 
The rest of the paper is organized as follows. Section 2 develops the baseline model and its extensions, characterizes the macroeconomic equilibrium and the steady state, and also derives the social optimum. A number of analytical results are also derived in this context, specifying the consumption and income taxes/subsidies that would enable the decentralized economy to attain the first-best scenario. Then Section 3 extends the model to include a specific source for endogenous growth: public capital. The section also identifies numerically the fiscal policies that enable the decentralized economy to replicate the social optimum for the generalized model, and links that with growth and welfare. Section 4 concludes the paper. An online appendix studies the growth and welfare effects of several fiscal policy experiments along the balanced growth path. In addition, the online appendix also contains the proofs of propositions given in this paper.

\section{The Main Model}

We consider a dynamic general equilibrium model of a closed economy that allows for fully endogenous growth. In that context, first, we consider the simplest case of an $A K$ model. Next, we complement this case by introducing a public good in the production function. Time is considered to be continuous. There is a large number of households and firms, the respective number of which we normalize to unity. Households are homogeneous and exhibit positional preferences. They derive utility from own consumption, own wealth and wealth relative to some wealth reference level (relative wealth) as our baseline model. ${ }^{10}$ As an extension to this baseline case, we consider the inclusion of positional preferences with respect to consumption.

\subsection{The Baseline Model}

Households. Individuals derive utility from own consumption, own wealth and relative wealth. Relative wealth is given by individual wealth, $K$, relative to some wealth reference level $\bar{K}: K / \bar{K}$. As households are homogeneous in our framework, we consider the economy's average wealth level as a natural choice for a household's wealth reference level. ${ }^{11}$

\footnotetext{
${ }^{10}$ As a special case, we investigate what happens when households do not exhibit a preference for relative wealth.

${ }^{11}$ In a model with heterogeneous households, a household's reference level may be specified more generally (cf. Eckerstorfer and Wendner 2013).
} 
In what follows, we use the terms relative wealth and conspicuous wealth interchangeably. An individual household considers the wealth reference level as exogenous.

The quasi-concave instantaneous utility function is given by: ${ }^{12}$

$$
\begin{aligned}
u\left(C, K, \frac{K}{\bar{K}}\right) & =\frac{1}{\gamma}\left[C K^{\xi\left(1-\eta_{k}\right)}\left(\frac{K}{\bar{K}}\right)^{\eta_{k}}\right]^{\gamma} \\
& =\frac{1}{\gamma}\left[C K^{\eta_{k}+\xi\left(1-\eta_{k}\right)} \bar{K}^{-\eta_{k}}\right]^{\gamma}, \quad-\infty<\gamma<1,0 \leq \eta_{k}<1, \quad \xi \geq 0,
\end{aligned}
$$

that is, households exhibit constant relative risk aversion, with absolute elasticity of marginal utility of consumption equal to $(1-\gamma)$. Parameter $\xi$ indexes the preference for wealth. Suppose for the moment that $\eta_{k}=0$. If $\xi=0$, the household does not exhibit preferences with respect to wealth. With $\xi>0$, households value wealth in addition to consumption. Parameter $\eta_{k}$ indexes the degree of concern for relative wealth. Specifically, if $\xi=1, \eta_{k}$ represents the marginal degree of positionality (cf. Johansson-Stenman et al. 2002) with respect to wealth (see below). ${ }^{13}$

The intertemporal utility function is given by:

$$
\int_{0}^{\infty} \frac{1}{\gamma}\left[C K^{\eta_{k}+\xi\left(1-\eta_{k}\right)} \bar{K}^{-\eta_{k}}\right]^{\gamma} e^{-\beta t} d t, \beta>0,
$$

where $\beta$ is the household's constant rate of time preference. Facing market prices that are given, the reference level $\bar{K}$, and equipped with perfect foresight, the household chooses a plan $\{C(t)\}_{t=0}^{\infty}$ so as to

$$
\begin{aligned}
& \max \int_{0}^{\infty} \frac{1}{\gamma}\left[C K^{\eta_{k}+\xi\left(1-\eta_{k}\right)} \bar{K}^{-\eta_{k}}\right]^{\gamma} e^{-\beta t} d t \\
& \text { s.t. } \\
& \dot{K}=\left(1-\tau_{y}\right) Y_{K} K-\left(1+\tau_{c}\right) C-T-\delta_{k} K, \\
& \lim _{t \rightarrow \infty} K_{t} e^{-\int_{0}^{t} r_{s} d s} \geq 0 .
\end{aligned}
$$

\footnotetext{
${ }^{12}$ The utility function we consider is multiplicative (rather than additive) in consumption and capital as it is more general than an additive specification, which is because the marginal rate of substitution between the arguments is not constant. Both formulations are widely used in the literature.

${ }^{13}$ A marginal degree of positionality reflects the share of marginal utility of individual consumption or wealth that is due to the fact that own consumption or wealth raises the ratio $C / \bar{C}$ or $K / \bar{K}$, ceteris paribus.
} 
The first constraint in (0) is the household's flow budget constraint, where $Y_{K} \equiv \partial Y / \partial K$ denotes the rental rate of capital. Moreover, $\tau_{y}$ and $\tau_{c}$ are respectively the income- and consumption tax rate, and $T$ denotes lump sum taxes. In our framework, the labor-leisure decision is exogenous. As shown below, in the absence of a preference for (relative) wealth, the optimal consumption- and income tax rates are zero.

The second constraint in (0) is the No-Ponzi-Game condition, where the rate of interest $r$ is determined in competitive factor markets, as discussed below. In equilibrium, the transversality condition requires the No-Ponzi-Game condition to hold with strict equality.

Firms. A homogeneous output, $Y$, is produced by capital according to the linear technology (Rebelo 1991):

$$
Y=A K, A>0
$$

where $A$ is total factor productivity. The depreciation rate of capital is $\delta_{k} \in[0,1]$. We assume $\left(A-\delta_{k}\right) \geq 0$ to ensure a non-negative net productivity. Given competitive factor markets, the rate of interest, $r$, is given by $A-\delta_{k}$, where

$$
A-\delta_{k}>\beta
$$

ensures positivity of growth rates along the balanced growth path (BGP). In words, Assumption (A.1) implies that the rate of interest strictly exceeds the rate of time preference.

Government. The government's instruments, in our baseline model, include a consumption tax, $\tau_{c}$, an income tax, $\tau_{y}$, and a lump-sum tax, $T$. These taxes are levied in order to address externalities stemming from preferences for wealth as well as from relative wealth. The reason for including a consumption tax, despite labor supply being exogenous, is because of the consumption-savings distortions generated by the pattern of household preferences, as discussed above. Therefore, the consumption tax does not act as a lump-sum tax and may be used to correct for potential distortions. The income tax essentially acts as a wealth tax as all income in the $A K$ model is capital income. 
In each period, the government runs a balanced budget. ${ }^{14}$ The government budget constraint can be expressed as

$$
\tau_{c} C+\tau_{y} Y+T=0
$$

As we consider a closed economy, in the baseline model, the aggregate resource constraint is given by:

$$
\dot{K}=Y-C-\delta_{k} K
$$

In Subsection 3.1 below, we consider a generalized version of this baseline model. In that framework, the government also undertakes productive expenditures, $G$, which are financed by the same set of taxes as above, affecting the aggregate resource constraint.

\subsubsection{Macroeconomic Equilibrium}

Let the current-value Hamiltonian be given by:

$$
H=\frac{1}{\gamma}\left[C K^{\eta_{k}+\xi\left(1-\eta_{k}\right)} \bar{K}^{-\eta_{k}}\right]^{\gamma}+\lambda\left[\left(1-\tau_{y}\right) Y_{K} K-\left(1+\tau_{c}\right) C-T-\delta_{k} K\right]
$$

An interior solution satisfies the following necessary first-order conditions.

$$
\begin{aligned}
& \frac{\partial H}{\partial C}=C^{\gamma-1} K^{\xi\left(1-\eta_{k}\right) \gamma+\eta_{k} \gamma} \bar{K}^{-\eta_{k} \gamma}-\lambda\left(1+\tau_{c}\right)=0 \\
& \frac{\partial H}{\partial K}=\left[\left(1-\eta_{k}\right) \xi+\eta_{k}\right] C^{\gamma} K^{\left(\left(1-\eta_{k}\right) \xi+\eta_{k}\right) \gamma-1} \bar{K}^{-\eta_{k} \gamma}+\lambda\left[\left(1-\tau_{y}\right) A-\delta_{k}\right]=\beta \lambda-\dot{\lambda}
\end{aligned}
$$

Ex post, as households are homogeneous $\bar{K}=K$. The first-order conditions then imply:

$$
\begin{aligned}
& C^{\gamma-1} K^{\xi\left(1-\eta_{k}\right) \gamma}=\lambda\left(1+\tau_{c}\right), \\
& {\left[\left(1-\eta_{k}\right) \xi+\eta_{k}\right] C^{\gamma} K^{\left(1-\eta_{k}\right) \xi \gamma-1}+\lambda\left[\left(1-\tau_{y}\right) A-\delta_{k}\right]=\beta \lambda-\dot{\lambda} .}
\end{aligned}
$$

Next, we define the normalized variables $c \equiv C / K, y \equiv Y / K$. Using (0) in (0) yields

$$
\left[\left(1-\eta_{k}\right) \xi+\eta_{k}\right] c\left(1+\tau_{c}\right)+\left(1-\tau_{y}\right) A-\delta_{k}=\beta-\frac{\dot{\lambda}}{\lambda} .
$$

\footnotetext{
${ }^{14}$ We do not include government bonds in our analysis, because this only introduces a no-arbitrage condition, which determines the same rate of interest as given above (A.1).
} 
Differentiating (0) and taking resource constraint (0) into account gives

$$
(\gamma-1) \frac{\dot{C}}{C}+\xi\left(1-\eta_{k}\right) \gamma\left(A-c-\delta_{k}\right)=\frac{\dot{\lambda}}{\lambda}
$$

Next, using (0) in (0) and considering $\dot{c} / c=\dot{C} / C-\dot{K} / K$ yields:

$$
\frac{\dot{c}}{c}=\frac{\left(1-\eta_{k}\right) \xi \gamma\left(A-c-\delta_{k}\right)+\left[\left(1-\eta_{k}\right) \xi+\eta_{k}\right]\left(1+\tau_{c}\right) c+\left(1-\tau_{y}\right) A-\delta_{k}-\beta}{1-\gamma}-\left(A-c-\delta_{k}\right)
$$

Differential equation (0) represents the model's one-dimensional dynamic system in the dynamic variable $c$. As in the basic model without a preference for (relative) wealth, there is no transitional dynamics, and the economy jumps from one steady state to another. ${ }^{15}$ Below, in our extended model with public capital in the production function, there is transitional dynamics because of the presence of an additional stock variable.

The economy will in steady state follow a balanced growth path, defined as a path along which $Y, C$ and $K$ grow at constant rates. It can easily be verified that these variables grow at the same constant growth rate $\Gamma$ along a BGP. That is, in a steady state, $\dot{c}=0$ where $c$ solves for

$$
c^{*}=\frac{\beta-\gamma\left(A-\delta_{k}\right)\left(1+\left(1-\eta_{k}\right) \xi\right)+A \tau_{y}}{1-\gamma\left(1+\left(1-\eta_{k}\right) \xi\right)+\left(\xi\left(1-\eta_{k}\right)+\eta_{k}\right)\left(1+\tau_{c}\right)},
$$

where an asterisk (*) indicates steady state values for the decentralized economy. An intertemporal elasticity of substitution less than unity $(\gamma<0)$ is sufficient for a positive consumption-to-capital ratio. Noting (0), the endogenous growth rate of per capita consumption (income) is given by $\Gamma^{*}=A-\delta_{k}-c^{*}$.

Based on this baseline model, we will analyze two cases of special interest. First, we study the case in which households do not have concern for relative wealth, i.e., $\xi>0, \eta_{k}=0$. Second, we consider positionality in wealth, i.e., $\xi=1, \eta_{k}>0$. Before that, however, we need to spell out the socially optimal allocation. From this allocation, by comparing with the market economy's allocation, we derive optimal consumption- and income tax rates for the BGP below.

\footnotetext{
${ }^{15}$ It is worthwhile to note that in the paper with positional preferences by Carroll et al. (1997) does have transitional dynamics within an AK framework. This is due to the positionality being of the nature of an accumulated stock of habits, unlike in our case.
} 


\subsubsection{Baseline Model: The Social Optimum}

We adopt the primal approach to derive the socially optimal allocation. In contrast to private households, the government takes into account that $\bar{K}=K$ in its optimizing exercise. The current value Hamiltonian of the government's problem is given by:

$$
\hat{H}=\frac{1}{\gamma}\left[C K^{\xi\left(1-\eta_{k}\right)}\right]^{\gamma}+\hat{\lambda}\left[A K-C-\delta_{k} K\right]
$$

Taking the necessary first-order conditions with respect to $C$ and $K$ and following the same steps as in the decentralized economy, we obtain the growth rate of the consumption-tocapital ratio:

$$
\frac{\dot{c}}{c}=\frac{\left(1-\eta_{k}\right) \xi \gamma\left[A-c-\delta_{k}\right]+\left(1-\eta_{k}\right) \xi c+A-\delta_{k}-\beta}{1-\gamma}-\left(A-c-\delta_{k}\right)
$$

Again, the economy will, in a steady state, follow a BGP. Along the BGP $\dot{c}=0$, implying that the optimal $c$ is given by:

$$
\hat{c}=\frac{\beta-\gamma\left(A-\delta_{k}\right)\left(1+\left(1-\eta_{k}\right) \xi\right)}{(1-\gamma)\left(1+\left(1-\eta_{k}\right) \xi\right)},
$$

where a hat $\left({ }^{\wedge}\right)$ indicates socially optimal values. Variables $C, K$, and $Y$ grow at the same constant endogenous growth rate, $\hat{\Gamma}=A-\delta_{k}-\hat{c}$.

\subsubsection{Distortions and Optimal Taxation}

Given that income and consumption taxes impact on the economy in very different ways, what tax and expenditure rates in the decentralized economy will replicate the social planner's optimum? Let these choices be represented by the vector $\left(\hat{\tau}_{c}, \hat{\tau}_{y}\right)$. Then, by definition, this vector is a description of optimal fiscal policy in the decentralized economy. To determine these optimal choices, we will compare the equilibrium outcome (0) with the decentralized outcome as given by (0), or, equivalently, by comparing (0) with (0). As a result, we obtain the optimal relationship between the income and consumption tax rates: 


$$
\tau_{y}=\frac{\left[\tau_{c}\left(\xi\left(1-\eta_{k}\right)+\eta_{k}\right)+\eta_{k}\right] \hat{c}}{A}
$$

As shown by (0), only one tax rate is required to be chosen (independently) by the government to attain the first-best equilibrium. This is because we face a single externality here - an individual's saving decision impacts on both own and average wealth, and thereby on relative wealth of all other individuals. An income tax is able to internalize this externality. However, given that labor supply is exogenous, this could alternatively be performed by a consumption tax. This interesting result extends to a situation in which households are not only positional with respect to wealth but also, simultaneously, with respect to consumption. In that case, the nature of this externality (in individuals' consumption-saving decision) remains the same, although its size differs, and so the value of the corrective consumption/income tax would be different.

A useful benchmark, then, is to derive the tax on consumption, $\hat{\tau}_{c}$, when $\tau_{y}=0$ as well as on income, $\hat{\tau}_{y}$, when $\tau_{c}=0$.

$$
\hat{\tau}_{c}=\left\{\begin{array}{cc}
-\frac{\eta_{k}}{\eta_{k}+\left(1-\eta_{k}\right) \xi} & \text { if } \xi>0 \text { or } \eta_{k}>0 \\
0 & \text { if } \xi=0 \text { and } \eta_{k}=0
\end{array}, \quad \hat{\tau}_{y}=\frac{\eta_{k} \hat{c}}{A}\right.
$$

As is evident either instrument, by itself, can be used to attain the social optimum. ${ }^{16}$

\section{Proposition 1. (Optimal Taxation when wealth is in the utility function)}

If wealth is an argument in the utility function, and $\eta_{k}>0$, then the optimal tax rates required to attain the first-best differ from zero and take the values given by (0). In this case, the optimal consumption tax is negative (i.e., a consumption subsidy), while the optimal income tax is positive. A higher value for $\xi$ lowers the consumption subsidy.

The presence of concern for relative wealth introduces a distortion and gives rise to optimal tax rates being different from zero. The distortion induces households to over-save. Therefore, the optimal consumption tax is negative, and the optimal income tax is positive. In fact, the

\footnotetext{
${ }^{16}$ Notice that the second line in $(0)$ cannot be derived from the expression provided in the first line. Rather, one needs to compare the optimal consumption growth rate $(0)$ with the decentralized consumption growth rate $(0)$. A parallel statement holds for the proceeding model versions.
} 
optimal consumption tax rate equals the negative of the marginal degree of positionality regarding relative wealth. Let $v\left(C, K, K^{r}\right) \equiv u(C, K, K / \bar{K})$, with $K^{r} \equiv K / \bar{K}$. As in Johansson-Stenman et al. (2002), the marginal degree of positionality with respect to wealth is generally defined by

$$
M D P_{k}=\frac{\left(\partial v(.) / \partial K^{r}\right)\left(\partial K^{r} / \partial K\right)}{\left(\partial v(.) / \partial K^{r}\right)\left(\partial K^{r} / \partial K\right)+(\partial v(.) / \partial K)}=\frac{\eta_{k}}{\eta_{k}+\left(1-\eta_{k}\right) \xi} .
$$

Consider a rise in $K$. The numerator shows the marginal utility of wealth stemming only from a rise in relative wealth. The denominator shows the marginal utility of wealth from both sources - indirect (via the change in relative wealth) and direct (via the change in absolute wealth). The ratio, then, identifies the share of marginal utility of wealth that is due to the fact that own wealth raises the ratio $K / \bar{K}$, ceteris paribus. That is, the optimal consumption tax rate is the Pigouvian tax rate internalizing the externality due to over-saving. A rise in the degree of positionality raises the (absolute values) of the optimal tax rates (or subsidies).

\section{Corollary 1.}

If and only if $\eta_{k}=0$, the optimal consumption- and income tax rates equal zero. In particular, positional preferences with respect to wealth always introduce a distortion.

Corollary 1 implies that positional preferences with respect to wealth are distortionary whether or not households exhibit a preference for absolute wealth. This leads us to a brief discussion of the role of the preference for absolute wealth, $\xi$.

\section{Corollary 2.}

Consider $\xi>0$. The preference for absolute wealth is non-distortionary. However, $\xi$ does impact on the strength of the distortion once positionality in wealth exists, and thereby on the magnitudes of the corrective income- or consumption tax rates in that case.

A preference for absolute wealth only is non-distortionary, as established by Judd (1985) and Chamley (1986). However, once $\eta_{k}>0, \xi$ does impact on the strength of the distortion. A rise in $\xi$ lowers the distortion and thereby the (absolute values of the) optimal consumptionand income tax rates. In (0), this is directly seen for the optimal consumption tax rate. However, it also applies to the optimal income tax rate - via its impact on $\hat{c}$. 
Consider first $\xi=0$ and $\eta_{k}>0$. In this case, the optimal consumption subsidy assumes the extreme value of $\hat{\tau}_{c}=-1$. The optimal consumption tax rate equals the marginal rate of substitution of $\bar{K}$ for $K$. In our framework, considering equation (0), this marginal rate of substitution equals -1 in equilibrium. ${ }^{17}$ Consider next a rise in $\xi$. The marginal degree of positionality declines in $\xi$. As seen in (0), a rise in $\xi$ does not impact on either the numerator or the first term of the denominator. However, $\xi$ raises the direct marginal utility of wealth (cf. the second term in the denominator). The decline in the marginal degree of positionality translates into a decline in the optimal consumption subsidy. Likewise, the decline in the marginal degree of positionality translates into a decline in the optimal income tax rate (via a lowering in $\hat{c}$ ). Consider finally the case where $\xi=1$. In this case, the degree of positionality equals $\eta_{k}$, and the optimal consumption tax rate equals $-\eta_{k}$.

As a policy prescription, only based on the baseline model, consumption should be subsidized and income be taxed in order to internalize the distortion stemming from the wealth positionality. Put differently, the Pigouvian consumption subsidy (income tax) prevents people from engaging in the rat race for attaining a higher social status via over-saving. The presence of a preference for absolute wealth $(\xi>0)$ does not change this result. ${ }^{18}$

In the proceeding subsection, we show that this policy prescription is strongly modified when households are also concerned with relative consumption, in addition to relative wealth.

\subsection{The Impact of Consumption Positionality}

We now extend our baseline model to include positionality with respect to consumption. Households are concerned not only about relative wealth but also about their consumption relative to others. This is captured by an additional term, $C / \bar{C}$, in the utility function, where $\bar{C}$ represents some consumption reference level and the term $C / \bar{C}$ is referred to as relative

\footnotetext{
${ }^{17}$ This result holds in our multiplicative specification, but is not restricted to this particular functional form. Even a subtractive specification yields the same marginal rate of substitution.

${ }^{18}$ Though, via the impact of $\xi$ on the $M D P_{k}$, the presence of a preference for absolute wealth impacts on the levels of the optimal taxes.
} 
consumption. In this extended framework, the quasi-concave instantaneous utility function is given by

$$
\begin{aligned}
u\left(C, \frac{C}{\bar{C}}, K, \frac{K}{\bar{K}}\right) & =\frac{1}{\gamma}\left[C^{1-\eta_{c}}\left(\frac{C}{\bar{C}}\right)^{\eta_{c}} K^{\xi\left(1-\eta_{k}\right)}\left(\frac{K}{\bar{K}}\right)^{\eta_{k}}\right]^{\gamma} \\
& =\frac{1}{\gamma}\left[C \bar{C}^{-\eta_{c}} K^{\eta_{k}+\xi\left(1-\eta_{k}\right)} \bar{K}^{-\eta_{k}}\right]^{\gamma}, \quad-\infty<\gamma<1,0 \leq \eta_{c}<1,0 \leq \eta_{k}<1, \quad \xi \geq 0 .
\end{aligned}
$$

Parameter $\eta_{c}$ indexes the degree of concern for relative consumption. In fact, $\eta_{c}$ represents the marginal degree of positionality with respect to consumption, $M D P_{c}$. That is, $M D P_{c}=\eta_{c}$ is the share of marginal utility of consumption that is due to the fact that own consumption raises the ratio $C / \bar{C}$, ceteris paribus.

The optimization problem for the consumer remains the same as in (0) with the utility function modified by the consumption positionality in line with (0). Taking the first-order conditions with respect to $C$ and $K$ and following the same steps as in the baseline model leads us to the expression for the growth rate of the consumption-to-capital ratio:

$$
\frac{\dot{c}}{c}=\frac{\left(1-\eta_{k}\right) \xi \gamma\left(A-c-\delta_{k}\right)+\left[\left(1-\eta_{k}\right) \xi+\eta_{k}\right]\left(1+\tau_{c}\right) c+\left(1-\tau_{y}\right) A-\delta_{k}-\beta}{1-\left(1-\eta_{c}\right) \gamma}-\left(A-c-\delta_{k}\right)
$$

Along a BGP, $\dot{c}=0$, the consumption-to-capital ratio assumes its steady state value $c^{*}$, and the endogenous growth rate of per capita consumption and income becomes $\Gamma^{*}=A-\delta_{k}-c^{*}$. Clearly, the steady state values, $\left(c^{*}, \Gamma^{*}\right)$, of the model with a consumption externality differ from those of the baseline model (though the latter can be recovered by setting $\eta_{c}=0$ in (0)).

\section{Proposition 2. (Impact of preferences for (relative) wealth and consumption on growth)}

The preference for (absolute) wealth as well as both consumption positionality $\left(\eta_{c}>0\right)$ and wealth positionality $\left(\eta_{k}>0\right)$ impact on the endogenous growth rate of per capita consumption and income $\Gamma^{*}$. Suppose $\tau_{y}=0=\tau_{c}$ and $0 \leq \xi \leq 1$. Assume $\gamma<0$, as empirically strongly supported. Along the BGP,

$$
\frac{\partial \Gamma^{*}}{\partial \eta_{c}}>0\left(\frac{\partial \Gamma^{*}}{\partial \eta_{c}}<0 \Leftrightarrow \gamma>0\right)
$$


$\frac{\partial \Gamma^{*}}{\partial \eta_{k}}>0$

If $\eta_{c}=\eta_{k}=0, \frac{\partial \Gamma^{*}}{\partial \xi}>0$.

\section{Proof. $\quad$ See Appendix A.1. ${ }^{19}$}

There is overwhelming empirical evidence for the elasticity of intertemporal substitution to be lower than one $(\gamma<0){ }^{20} \mathrm{We}$ address this case to discuss Proposition 2. The other case, in which $\gamma>0$, can be argued in a parallel way. Proposition 2 is explained by the impact of the positionality parameters, $\eta_{c}$ and $\eta_{k}$, on the (long-run) elasticities of intertemporal substitution: $1 /\left(1-\gamma\left(1-\eta_{c}\right)\right)$ for consumption; $1 /\left(1-\gamma \xi\left(1-\eta_{k}\right)\right)$ for wealth. Notice that the elasticities differ from the inverses of the respective elasticities of marginal utility. A rise in $\eta_{c}$ or $\eta_{k}$ raises the long-run elasticities of intertemporal substitution, once $\gamma<0$. Intuitively, consider a rise in $\eta_{c}$ (a parallel argument can be provided for a rise in $\eta_{k}$ ). Considering (0), ceteris paribus, this rise leads an individual household to raise her steady state consumption growth rate in a bid to outshine the others. A rise in $\eta_{c}$ raises the long-run elasticity of intertemporal substitution of $C$, thereby lowering the desire for consumption smoothing. As a consequence, households prefer a higher consumption growth rate over a higher initial consumption level in response to a rise in $\eta_{c}$. Finally, a rise in the preference for wealth, $\xi$, raises growth, as households increase saving regardless of positional preferences.

This result is very much in line with the idea that positional preferences give rise to more economic activity or a higher endogenous growth rate. In fact, Adam Smith $(1759,1976)$ notes that "With the most unrelenting industry he labours night and day to acquire talents superior to all his competitors. He endeavours next to bring those talents into public view. ...

\footnotetext{
${ }^{19}$ The appendices are not part of the published paper. They are available online (and can be obtained from the authors upon request).

${ }^{20}$ Hall (1988, p.350) favors a value for the elasticity of marginal utility of consumption of (at most) 0.2. Other empirical estimates include Grossman and Shiller (1981), and Mankiw (1981, 1985) or Constantinides (1990). All of these authors present evidence for that parameter to significantly fall short of unity. Hansen and Singleton (1983) present evidence for this parameter to be greater than unity, though. Their adopted approach, however, was criticized by Hall (1988, p.345).
} 
It is this which first prompted them to cultivate the ground, to build houses, to found cities and commonwealths, and to invent and improve all the sciences and arts, which ennoble and embellish human life; which have entirely changed the whole face of the globe". More recently, Schulte (2014) discusses empirical studies emphasizing that due to social comparisons we are too busy to enjoy life.

Social comparisons change our saving- and consumption behavior. Whether or not social comparisons change this behavior in a non-optimal way is studied next.

Social Optimum. We now go on to analyze the distortionary impact of the consumption positionality. In the social optimization problem, the planner internalizes the externalities by choosing $\bar{C}=C$ in addition to $\bar{K}=K$ at the outset. The resulting optimal growth rate of the consumption-to-capital ratio is given by:

$$
\frac{\dot{c}}{c}=\frac{\left(1-\eta_{k}\right) \xi \gamma\left[A-c-\delta_{k}\right]+\left[\left(1-\eta_{k}\right) \xi /\left(1-\eta_{c}\right)\right] c+A-\delta_{k}-\beta}{1-\left(1-\eta_{c}\right) \gamma}-\left(A-c-\delta_{k}\right)
$$

Comparing (0) with (0) enables us to derive the optimal consumption- and income tax rates.

As before, in (0), $\hat{\tau}_{c}$ refers to the case in which $\tau_{y}=0$, and $\hat{\tau}_{y}$ refers to the case in which $\tau_{c}=0$

$\hat{\tau}_{c}=\left\{\begin{array}{cc}-\frac{\eta_{k}\left(1-\eta_{c}\right)-\eta_{c}\left(1-\eta_{k}\right) \xi}{\left(1-\eta_{c}\right)\left[\left(1-\eta_{k}\right) \xi+\eta_{k}\right]} & \text { if } \xi>0 \text { or } \eta_{k}>0 \\ 0 & \text { if } \xi=0 \text { and } \eta_{k}=0\end{array}, \quad \hat{\tau}_{y}=\frac{\left[\eta_{k}\left(1-\eta_{c}\right)-\eta_{c}\left(1-\eta_{k}\right) \xi\right] \hat{c}}{A\left(1-\eta_{c}\right)}(0)\right.$

\section{Proposition 3. (Optimal taxation with consumption positionality)}

(i) The optimal consumption- and income taxes are given by (0). Imposing either the optimal consumption tax or the optimal income tax enables the decentralized economy to attain the first-best optimum.

(ii) If and only if the marginal degree of positionality of consumption matches that of wealth, both optimal tax rates equal zero: $\quad M D P_{c}=M D P_{k} \Leftrightarrow \eta_{c}=\frac{\eta_{k}}{\left(1-\eta_{k}\right) \xi+\eta_{k}}$. 
Proposition 3 immediately follows from considering the numerators in (0). The first insight is that the first-best can be attained by either an optimal consumption tax or an optimal income tax. In spite of the presence of two externalities - consumption positionality and wealth positionality - only one tax instrument is required to attain the social optimum. The reason is that labor supply is exogenous. That is, both consumption- and wealth positionality distort only the consumption-saving decision. As a consequence, only one instrument is needed to correct for the distortionary effects of positionality with respect to consumption in addition to wealth.

The second insight is that - in spite of positional preferences - optimal tax rates may be equal to zero. Proposition 3 identifies two cases in which this happens. First, as expected, $\eta_{c}=\eta_{k}=0$, when preferences are not positional. Second, also if $M D P_{c}=M D P_{k}$, the optimal consumption- or income tax rates are equal to zero. In this case, the incentive to over-save exactly offsets the incentive to over-consume. That is, $\eta_{c}>0, \eta_{k}>0$ both raise the endogenous growth rate. However, once the condition stated in Proposition 3 is satisfied, this rise of the growth rate turns out to be optimal. Specifically, in case $\xi=1, M D P_{c}=M D P_{k}$ is equivalent to $\eta_{c}=\eta_{k} \geq 0$.

\section{Corollary 3. (Non-distortion of consumption positionality)}

Consider $\eta_{k}=\xi=0$. Then, consumption positionality (by itself) is not distortionary. If either $\eta_{k}>0$ or $\xi>0$, then consumption positionality is distortionary.

While wealth positionality always introduces a distortion (provided $M D P_{k} \neq M D P_{c}$ ) irrespective of whether or not $\eta_{c}>0$, consumption positionality only introduces a distortion when $\eta_{k}>0$ or $\xi>0$. This asymmetry implies that cultures in which people are positional with respect to consumption only, no distortion is introduced. The endogenous growth rate increases - though, in an optimal way. However, in a culture in which people are positional with respect to wealth, a distortion is always introduced, i.e., people over-save. The reason is that with $\eta_{k}=\xi=0$ the same Keynes-Ramsey rule holds in the decentralized- and the centralized solutions. The consumption positionality does not impact on the optimal consumption growth rate differently between the decentralized- and the centralized economy. However, once either $\eta_{k}>0$ or $\xi>0$, the Keynes-Ramsey rule differs between the 
decentralized- and the centralized economy. This is because the derivative of the Hamiltonian with respect to the capital stock contains a term, the marginal utility of wealth, that itself depends on the consumption externality. Individuals do not internalize this externality, whereas the government does so. As a consequence, a modified Keynes-Ramsey rule requires the government to choose a capital stock that is affected by the strength of the consumption externality. So, a wealth externality is always distortionary (provided $M D P_{k} \neq M D P_{c}$ ), regardless of whether or not we have a consumption externality, and this is one of the important results in our paper.

Considering (0), both the signs and the magnitudes of the optimal tax rates depend on the difference $\left(M D P_{c}-M D P_{k}\right)$. If this difference is positive (negative), then $\hat{\tau}_{c}>0, \hat{\tau}_{y}<0$ $\left(\hat{\tau}_{c}<0, \hat{\tau}_{y}>0\right)$. This result implies a policy prescription. Cultures in which $\left(M D P_{c}-M D P_{k}\right)>0$, optimal corrective taxation requires $\hat{\tau}_{c}>0, \hat{\tau}_{y}<0$. Anecdotal evidence would associate "southern countries" with this pattern of positional preferences. Likewise, cultures in which $\left(M D P_{c}-M D P_{k}\right)<0$, optimal corrective taxation requires $\hat{\tau}_{c}<0, \hat{\tau}_{y}>0$. Anecdotal evidence would associate "northern countries" (with Protestant ethic) with this pattern of positional preferences.

Table 1. Optimal fiscal policy under positional preferences

\begin{tabular}{lccc}
\hline \multicolumn{2}{c|}{ Baseline Model } & Consumption Positionality \\
\hline$\xi>0, \eta_{k}=0$ & $\xi>0, \eta_{k}>0$ & $\xi>0, \eta_{k}>0, \eta_{c}>0$ \\
\hline$\hat{\tau}_{y}$ & 0 & $\frac{\eta_{k} c}{A}$ & $\frac{\left[\eta_{k}\left(1-\eta_{c}\right)-\eta_{c}\left(1-\eta_{k}\right) \xi\right] c}{A\left(1-\eta_{c}\right)}$ \\
$\hat{\tau}_{c}$ & 0 & $-\frac{\eta_{k}}{\left(1-\eta_{k}\right) \xi+\eta_{k}}$ & $-\frac{\eta_{k}\left(1-\eta_{c}\right)-\eta_{c}\left(1-\eta_{k}\right) \xi}{\left[\left(1-\eta_{k}\right) \xi+\eta_{k}\right]\left(1-\eta_{c}\right)}$ \\
\hline$\partial \hat{\tau}_{y} / \partial \xi$ & - & $-{ }^{*}$ \\
$\partial \hat{\tau}_{y} / \partial \eta_{k}$ & & + & $+{ }^{*}$ \\
$\partial \hat{\tau}_{y} / \partial \eta_{c}$ & & - & + \\
\hline$\partial \hat{\tau}_{c} / \partial \xi$ & & - & - \\
$\partial \hat{\tau}_{c} / \partial \eta_{k}$ & & & +
\end{tabular}




\begin{tabular}{l|c}
$\partial \hat{\tau}_{c} / \partial \eta_{c}$ & + \\
\hline Note. Sufficient conditions for the signs to hold. $* \gamma<0 ; * *(1-\eta) \xi>-\gamma(1-\eta)^{2}$
\end{tabular}

Note. Sufficient conditions for the signs to hold: * $\gamma<0$; ** $\left(1-\eta_{k}\right) \xi>-\gamma\left(1-\eta_{c}\right)^{2}$.

One special case, involving a discontinuity, deserves attention. If $\xi=0$ (and $\eta_{k}>0$ ), then the optimal consumption subsidy equals -1 , regardless of whether or not there is consumption positionality. In addition, the optimal consumption subsidy is independent of the magnitude of $\eta_{k}>0$.

However, once $\eta_{k}=0$, the optimal consumption subsidy discontinuously jumps to the value zero. The reason is given above already. With $\xi=0$ and $\eta_{k}=0$, consumption positionality is not distortionary, as shown in Corollary 3. With $\xi=0$ and $\eta_{k}>0$, consumption positionality is distortionary. In this case, though, independently of the specific value of $\eta_{k}$, the marginal rate of substitution of $\bar{K}$ for $K$ equals -1 , and so does the optimal consumption subsidy. The previous array summarizes the discussion on optimal fiscal policy.

\section{The Model with Public Capital}

In this section, we extend our baseline model to include a specific source for endogenous growth: public capital. The inclusion of public capital serves two purposes. First, public investment provides a "microfoundation" for endogenous growth - approximated by the AKformulation in the base model above. We derive the optimal tax rates in this endogenous growth framework and show that the results derived above are robust with respect to the introduction of this microfoundation for endogenous growth. Second, we use this refined framework to numerically simulate a variety of fiscal policy reforms below. These simulations show that the effects of fiscal policy reforms (on growth) are highly sensitive with respect to the wealth- and positionality parameters, $\eta_{c}, \eta_{k}, \xi$.

\subsection{The Impact of Public Capital in the Production Function}

While households face the same decision problem as in the (extended) base model above, the economic environment for firms and for the government changes. 
Firms. A homogeneous output, $Y$, is produced by private and public capital using a CES technology:

$$
Y=A\left[\alpha K^{-\rho}+(1-\alpha) K_{g}^{-\rho}\right]^{-1 / \rho}, 0<\alpha<1,-1<\rho<\infty
$$

The elasticity of substitution between private capital and the public good is given by $1 /(1+\rho)$. To ensure positivity of growth rates along the BGP (see below), we assume

$$
\alpha A-\delta_{k}>\beta
$$

The assumption implies that the private rate of interest strictly exceeds the rate of time preference, similar to (A.1).

Government. Here, in contrast to the baseline model, the government invests in public capital (infrastructure). Public capital evolves according to:

$$
\dot{K}_{g}=G-\delta_{g} K_{g}, G=g Y, 0<\delta_{g}<1
$$

where $G$ represents the flow of public expenditures for public capital, and $\delta_{g}$ is the rate of depreciation of public capital. The flow of public expenditures is a fixed share $g>0$ of output. As before, in each period, the government runs a balanced budget. The government budget constraint can be expressed as

$$
\tau_{c} C+\tau_{y} Y+T-g Y=0
$$

As we consider a closed economy, the aggregate resource constraint is given by:

$$
\dot{K}=Y(1-g)-C-\delta_{k} K
$$

The optimization problem for the decentralized economy remains the same as in the (extended) base model above, with the production function being modified by public capital 
in line with (0). We define the normalized variables, $y \equiv Y / K$ and $z \equiv K_{g} / K$, where $y=A\left[\alpha+(1-\alpha) z^{-\rho}\right]^{-1 / \rho}$, considering (0). Moreover, the rental rate of capital becomes $Y_{K}=\alpha A^{-\rho} y^{1+\rho} \cdot{ }^{21}$ Taking the first-order conditions with respect to $C$ and $K$ and following the same steps as in the baseline model leads us to the expression for the growth rate of the consumption-to-capital ratio:

$$
\begin{aligned}
\frac{\dot{c}}{c}= & \frac{\left(1-\eta_{k}\right) \xi \gamma\left((1-g) y-c-\delta_{k}\right)+\left[\left(1-\eta_{k}\right) \xi+\eta_{k}\right]\left(1+\tau_{c}\right) c+\left(1-\tau_{y}\right) Y_{K}-\delta_{k}-\beta}{1-\left(1-\eta_{c}\right) \gamma} \\
& -\left((1-g) y-c-\delta_{k}\right)
\end{aligned}
$$

We observe that replacing the term $(1-g) y$ with $A$ in (0) immediately yields the corresponding growth rate $(0)$ in the baseline model. From the two capital accumulation equations (0) and (0), it follows:

$$
\frac{\dot{z}}{z}=g \frac{y}{z}-\delta_{g}-(1-g) y+c+\delta_{k}
$$

Differential equations (0) and (0) represent the model's two-dimensional dynamic system in the dynamic variables $c$ and $z$.

The economy will in steady state follow a balanced growth path, defined as a path along which $Y, C, K$ and $K_{g}$ grow at constant rates. It can easily be verified that $Y, C, K$ and $K_{g}$ grow at the same constant growth rate $\Gamma^{*}$ along a BGP. That is, in a steady state, $\dot{c}=\dot{z}=0$. As can be easily verified, the steady state is a saddle point and is saddle point stable. In contrast to the baseline framework, this model with public capital exhibits a non-degenerate transitional dynamics. ${ }^{22}$

Social optimum. For analyzing the distortionary impact of the wealth- and consumption positionalities, we follow the steps presented above with two exceptions. First, the government has an additional control variable $g$, the share of government spending to GDP. Second, the government has an additional constraint regarding public capital accumulation,

\footnotetext{
${ }^{21}$ Notice that in our baseline model, $y=Y_{K}=A$.

${ }^{22}$ Existence and stability of a (the) steady state is discussed in a working paper version of this paper that is available at: http://www100.uni-graz.at/vwlwww/forschung/RePEc/wpaper/2014-09.pdf .
} 
given by (0). That is, public capital $K_{g}$ enters as an additional state variable, next to private capital $K$.

Taking the first-order conditions with respect to $C$ and $g$ as control variables, as well as with $K$ and $K_{g}$ as state variables into consideration leads us to the optimal growth rate of the consumption-to-capital ratio (details of the derivation are given in Appendix A.2):

$$
\frac{\dot{c}}{c}=\frac{\left(1-\eta_{k}\right) \xi \gamma\left[(1-g) y-c-\delta_{k}\right]+\xi\left(1-\eta_{k}\right) /\left(1-\eta_{c}\right) c+Y_{K}-\delta_{k}-\beta}{1-\gamma\left(1-\eta_{c}\right)}-(1-g) y+c+\delta_{k}
$$

Comparing the optimal solution (0) with the decentralized solution (0) provides us with two important results.

\section{Proposition 4. (Optimal taxation with public capital as the growth engine)}

Consider the model with public capital as the endogenous growth engine. If $g$ is chosen optimally, the optimal consumption- and income tax rates are given by:

$$
\hat{\tau}_{c}=\left\{\begin{array}{cc}
-\frac{\eta_{k}\left(1-\eta_{c}\right)-\eta_{c}\left(1-\eta_{k}\right) \xi}{\left(1-\eta_{c}\right)\left[\left(1-\eta_{k}\right) \xi+\eta_{k}\right]} & \text { if } \xi>0 \text { or } \eta_{k}>0 \\
0 & \text { if } \xi=0 \text { and } \eta_{k}=0
\end{array}, \quad \hat{\tau}_{y}=\frac{\left[\eta_{k}\left(1-\eta_{c}\right)-\eta_{c}\left(1-\eta_{k}\right) \xi\right] \hat{c}}{Y_{K}\left(1-\eta_{c}\right)}\right.
$$

Once $g$ is chosen optimally, the optimal consumption-and income tax rates, in a steady state, coincide with the ones implied by the AK-baseline model with $Y_{K}=A$.

Moreover, the optimal income tax rate, due to endogeneity of $\hat{c}$ and $\hat{z}$ (via $Y_{K}$ ), depends on the optimal government expenditure share g.

In (0), $\hat{\tau}_{c}$ refers to the case in which $\tau_{y}=0$, and $\hat{\tau}_{y}$ refers to the case in which $\tau_{c}=0$. The proposition shows that the optimal corrective tax rates, as derived for the baseline model, are robust with respect to the specification of the endogenous growth engine. However, it is important to note that here, in the extended model with public capital - which exhibits transitional dynamics - the optimal consumption- and income tax rates refer to the BGP only.

Proposition 4 shows the optimal corrective income tax rates only in implicit form. In contrast to the baseline model, it is not possible anymore to express $c, z$ explicitly. While the 
interpretation of the optimal tax rates equals that given for the baseline model, the levels are influenced not only by the preference- (positionality-) parameters, but also by the optimal government expenditure share $g$. The latter is roughly proportional to its productivity in the production function, $(1-\alpha)$. In order to gain some insight regarding the sensitivity of the optimal tax rates (as well as the variables, $c, z, g$ ) with respect to the preference parameters $\left(\eta_{c}, \eta_{k}, \xi\right)$, we employ numerical simulations.

We complete this section by deriving an expression for welfare. In Appendix A.3, we show that for both the decentralized as well as the centralized framework, the steady state welfare expression is given by:

$$
W=\frac{c^{\gamma\left(1-\eta_{c}\right)}}{\gamma\left\{\beta-\gamma \Gamma\left[\left(1-\eta_{c}\right)+\xi\left(1-\eta_{k}\right)\right]\right\}},
$$

where the growth rate $\Gamma=\Gamma(z)$. It should be noted that here welfare is expressed implicitly, as both $c$ and $z$ cannot be expressed explicitly in terms of parameters. Consider the main case, according to which $\gamma<0$. Then, a rise in the endogenous growth rate $\Gamma$ and a decline in the consumption-capital ratio raise welfare. In the following two sections, we employ (0) to quantify the respective impact of a variation of the preferences parameters and the introduction of several policy shocks (for differing values of the preference parameters) on steady state welfare.

\subsection{Numerical Simulations}

To get a flavor of how the optimal values of the corrective income- and consumption taxes are

affected by the key behavioral parameters of the model we calculate $\left(\hat{\tau}_{y}, \hat{\tau}_{c}, \hat{g}\right)$ based on benchmark parameter values commonly employed in the literature. In addition, we calculate the impact of the key behavioral parameters on steady state welfare, endogenous growth and the consumption-capital ratio (both of which are needed to explain the associated welfare changes).

Preference parameters are assigned the following values: $\beta=0.04, \gamma=-1.5$. The latter parameter gives rise to an intertemporal elasticity of substitution equal to $1 /(1-\gamma)=0.4$, as suggested by Guvenen (2006). Technology parameters are assigned the following values: $A=0.6, \alpha=0.8, \rho=1, \delta_{g}=\delta_{k}=0.08$. First, following common practice, we use the total 
factor productivity, A, as a scale parameter to help us obtain plausible values for the growth rate, and a value of $A=0.6$ achieves that. The value of $\alpha$ (which is the output-elasticity of private capital) is set at 0.8 , which is plausible if private capital is meant to include human capital, as in Romer (1986). This also implies that the elasticity of public capital is 0.2 , which is consistent with the empirical evidence provided by Gramlich (1994). There is not much empirical evidence on the elasticity of substitution between private and public capital (Lynde and Richmond, 1993, provides an exception); $\rho=1$, which corresponds to this elasticity being equal to $1 /(1+\rho)=0.5$, is one of the values for this parameter chosen by Chatterjee and Ghosh (2011). Finally, the depreciation rates for the private and public capital stocks are each set at $8 \%$ in line with Chatterjee and Ghosh (2011). ${ }^{23}$

Based on these benchmark values, we focus on the impact of different values of the key preference parameters $\left(\eta_{c}, \eta_{k}, \xi\right)$ on the optimal policy variables $\left(\hat{\tau}_{c}, \hat{\tau}_{y}, \hat{g}\right)$, as well as on the optimal variables $(\hat{c}, \hat{\Gamma}, \hat{W})$, where $\hat{W}$ indicates optimal steady state welfare.

We first briefly address the role of $\xi$, the preference for absolute- (as opposed to relative-) wealth. In Table 2 , we vary $\xi$ while having fixed $\left(\eta_{c}, \eta_{k}\right)=(0.4,0.4)$. These values of the positionality parameters are empirically supported. Compiling several empirical studies, Wendner and Goulder (2008) find that $\eta_{c}$ and $\eta_{k}$ are found to fall within the range, $\eta_{i} \in[0.2,0.4], i \in\{c, k\}$. Other studies find empirical evidence for even larger values of $\eta_{i}$ (cf. Johansson-Stenman et al. 2002, Solnick and Hemenway 1998, 2005). Newer empirical studies corroborate this evidence (Alvarez-Cuadrado et al. 2012, Dynan and Ravina 2007).

Table 2 reveals the strong impact of the preference for absolute wealth on the optimal corrective tax scheme. In fact, with $\xi=1, M D P_{c}=M D P_{k}$ and, according to Proposition 4, the optimal corrective tax rates are equal to zero. If $\xi<1$, for given $\left(\eta_{c}, \eta_{k}\right), M D P_{c}<M D P_{k}$ and the optimal consumption tax rate becomes negative (the optimal income tax rate becomes positive). The reverse holds for $\xi>1$, in which case $M D P_{c}>M D P_{k}$. That is, even if $\eta_{c}=\eta_{k}$, the optimal corrective tax structure depends on the preference for absolute wealth, $\xi$. For low values of $\xi$, it is optimal to subsidize consumption and tax income (at substantial rates). For

\footnotetext{
${ }^{23}$ See also Baxter and King (1993), where the value for the rate of depreciation of the capital stock in the US is chosen at $10 \%$.
} 
high values of $\xi$, it is optimal to tax consumption and subsidize income. This is the first policy lesson, to be drawn from Table 2 .

Table 2. The optimal levels of $\left(\hat{\tau}_{c}, \hat{\tau}_{y}, \hat{g}\right)$ as well as $(\hat{c}, \hat{\Gamma}, \hat{W})$ when $\xi$ is gradually increased, and $\eta_{c}=\eta_{k}=0.4$

\begin{tabular}{l|ccc|ccc}
\hline$\eta_{c}=\eta_{k}=0.4$ & $\hat{\tau}_{c}$ & $\hat{\tau}_{y}$ & $\hat{g}$ & $\hat{c}$ & $\hat{\Gamma}$ & $\hat{W} / \hat{W}(0)$ \\
\hline$\xi=0.2$ & -0.6154 & 0.2021 & 0.1881 & 0.2022 & 0.1157 & 1.1445 \\
$\xi=0.6$ & -0.2105 & 0.1014 & 0.1794 & 0.1885 & 0.1192 & 1.4370 \\
$\xi=1.0$ & 0.0000 & 0.0000 & 0.1711 & 0.1785 & 0.1204 & 1.7305 \\
$\xi=1.4$ & 0.1290 & -0.1040 & 0.1636 & 0.1704 & 0.1205 & 2.0228 \\
$\xi=1.8$ & 0.2162 & -0.2112 & 0.1568 & 0.1636 & 0.1200 & 2.3134 \\
\hline
\end{tabular}

NoTE. $(c, z, g)$ are simultaneously derived employing the benchmark parameter values.

Welfare is normalized so that $\hat{W}(\xi)=\hat{W}(0)=1$.

In the simulations, the government always chooses its expenditure share for public capital, $g$, optimally. In contrast to the simpler Barro (1990) model, in which $\hat{g}=(1-\alpha)$, here public capital is a stock rather than flow variable. As a consequence, $\hat{g}<(1-\alpha)$. This difference occurs as the advantage of a larger public investment share materializes only tomorrow whereas the cost in terms of foregone consumption is to be paid today. No such intertemporal consideration is present in the Barro (1990) model (cf. Futagami et al., 1993). ${ }^{24}$

The optimal expenditure share for public capital is affected by the preference for absolute wealth, $\xi$. A rise in $\xi$, by raising the marginal utility of consumption, increases the cost of foregone consumption today. Therefore, the higher is $\xi$, the more $\hat{g}$ falls short of $(1-\alpha)$.

In Table 2, welfare is normalized to unity for $\xi=0$. As $\xi$ increases, a value larger than unity indicates a higher welfare level compared to the welfare level for $\xi=0$. A rise in the importance of wealth, $\xi$, fosters savings. Thereby, the consumption-capital ratio decreases, and the endogenous growth rate rises. As a consequence, considering our welfare expression (0), it follows that welfare is increased. Table 2 shows that this increase in welfare is quite pronounced. That is, quantitatively, not only optimal tax rates but also optimal welfare

\footnotetext{
${ }^{24}$ For the stock formulation, the growth-maximizing share of public investment exceeds the welfare-maximizing share (cf. Escobar-Posada and Monteiro, 2015, or Futagami et al., 1993).
} 
responds significantly to a rise in the preference for absolute wealth. This is the second policy lesson, to be drawn from Table 2.

Next, we consider a variation in the positional preference for (relative) wealth. In Table 3, we vary $\eta_{k}$ while having set $\left(\eta_{c}, \xi\right)=(0,1)$. A gradual increase in $\eta_{k}$ has a substantive impact on the magnitude of the optimal corrective tax rates. Wealth positionality implies over-saving. As a consequence, the optimal corrective income tax rate is positive, and the corrective consumption tax rate is negative - and the more so the stronger is the positional preference for wealth.

A rise in the positional preference for wealth raises the consumption-capital ratio, and it lowers the optimal growth rate. Intuitively, in the pursuit to internalize the wealth externality, the social planner chooses a lower wealth level (in each period) along the BGP, which implies a higher consumption-wealth ratio. The lower wealth level is brought about by a lower growth rate of wealth (capital). That is, the endogenous growth rate along a BGP declines in $\eta_{k}$. As we assume that the elasticity of intertemporal substitution is less than unity $(\gamma<0)$, welfare expression (0) implies a decline in optimal welfare.

Table 3. The optimal levels of $\left(\hat{\tau}_{c}, \hat{\tau}_{y}, \hat{g}\right)$ as well as $(\hat{c}, \hat{\Gamma}, \hat{W})$ when $\eta_{k}$ is gradually increased, and $\eta_{c}=0, \xi=1$

\begin{tabular}{l|ccc|ccc}
\hline$\eta_{c}=0, \xi=1$ & $\hat{\tau}_{c}$ & $\hat{\tau}_{y}$ & $\hat{g}$ & $\hat{c}$ & $\hat{\Gamma}$ & $\hat{W} / \hat{W}(0)$ \\
\hline$\eta_{k}=0$ & 0.0000 & 0.0000 & 0.1419 & 0.2145 & 0.0908 & 1.0000 \\
$\eta_{k}=0.1$ & -0.1000 & 0.0793 & 0.1439 & 0.2173 & 0.0908 & 0.9564 \\
$\eta_{k}=0.2$ & -0.2000 & 0.1577 & 0.1460 & 0.2202 & 0.0907 & 0.9128 \\
$\eta_{k}=0.3$ & -0.3000 & 0.2351 & 0.1482 & 0.2233 & 0.0905 & 0.8693 \\
$\eta_{k}=0.4$ & -0.4000 & 0.3115 & 0.1505 & 0.2266 & 0.0902 & 0.8257 \\
$\eta_{k}=0.5$ & -0.5000 & 0.3872 & 0.1528 & 0.2300 & 0.0899 & 0.7823 \\
\hline
\end{tabular}

NOTE. $(c, z, g)$ are simultaneously derived employing the benchmark parameter values. Welfare is normalized so that $\hat{W}\left(\eta_{k}\right)=\hat{W}(0)=1$.

It is interesting to compare the effects of a rise in the preference for relative wealth, $\eta_{k}$, with those of a rise in the preference for absolute wealth, $\xi$. As discussed above, while the former implies a higher optimal consumption-capital ratio and a lower growth rate, the latter implies a lower $\hat{c}$ and a higher $\hat{\Gamma}$. This result is important, as it shows that a preference for relative 
wealth, via $\eta_{k}$, and a preference for absolute wealth, via $\xi$, impose opposite effects on the optimal corrective tax rates.

Finally, we consider a variation in the positional preference for (relative) consumption. In Table 4 , we vary $\eta_{c}$ while having fixed $\left(\eta_{k}, \xi\right)=(0,1)$.

Table 4. The optimal levels of $\left(\hat{\tau}_{c}, \hat{\tau}_{y}, \hat{g}\right)$ as well as $(\hat{c}, \hat{\Gamma}, \hat{W})$ when $\eta_{c}$ is gradually increased, and $\eta_{k}=0, \xi=1$

\begin{tabular}{l|ccc|ccc}
\hline$\eta_{k}=0, \xi=1$ & $\hat{\tau}_{c}$ & $\hat{\tau}_{y}$ & $\hat{g}$ & $\hat{c}$ & $\hat{\Gamma}$ & $\hat{W} / \hat{W}(0)$ \\
\hline$\eta_{c}=0$ & 0.0000 & 0.0000 & 0.1419 & 0.2145 & 0.0908 & 1.0000 \\
$\eta_{c}=0.1$ & 0.1111 & -0.0856 & 0.1454 & 0.2045 & 0.0968 & 1.2131 \\
$\eta_{c}=0.2$ & 0.2500 & -0.1847 & 0.1494 & 0.1932 & 0.1035 & 1.4925 \\
$\eta_{c}=0.3$ & 0.4286 & -0.3005 & 0.1539 & 0.1804 & 0.1113 & 1.8717 \\
$\eta_{c}=0.4$ & 0.6667 & -0.4377 & 0.1590 & 0.1658 & 0.1202 & 2.4106 \\
$\eta_{c}=0.5$ & 1.0000 & -0.6025 & 0.1648 & 0.1488 & 0.1307 & 3.2267 \\
\hline
\end{tabular}

NOTE. $(c, z, g)$ are simultaneously derived employing the benchmark parameter values.

Welfare is normalized so that $\hat{W}\left(\eta_{c}\right)=\hat{W}(0)=1$.

In Table 4 , we set $\xi=1$. Notice that without a preference for absolute wealth, that is $\xi=0$, the optimal corrective tax rates both equal zero, according to Proposition 4, regardless of the degree of positionality with respect to consumption. The more interesting case then is to consider a situation in which households are also concerned with absolute wealth $(\xi>0)$. The natural benchmark case is $\xi=1$, in which case $\eta_{c}$ and $\eta_{k}$ have the economic interpretation of the marginal degree of positionality with respect to consumption and wealth respectively.

If $\eta_{c}=0$, there is no distortion, and the optimal corrective tax rates both equal zero, in spite of $\xi>0$ (and in line with Corollary 2). In the pursuit to correct for over-consumption, a rise in $\eta_{c}$ raises the optimal corrective consumption tax rate and lowers the optimal corrective income tax rate (i.e., makes it a corrective subsidy).

A rise in the positional preference for consumption lowers the optimal consumption-capital ratio, and it raises the optimal growth rate (see Table 4). To internalize the consumption 
externality, the social planner needs to correct the consumption-savings decision of households. By raising the optimal consumption tax, the planner introduces a wedge between the price of consumption and the return on savings, thereby lowering consumption and raising savings. Consequently, the growth rate of capital increases, and the consumption-capital ratio declines. According to welfare expression (0), a rise in $\eta_{c}$ implies an increase in optimal welfare.

While this is economically intuitive, the take-home message is the following. The optimal corrective consumption- and income tax rates become substantial even for empirically supported magnitudes of the degree of positionality with respect to consumption (Wendner and Goulder, 2008). In fact, the optimal corrective consumption tax rate varies between zero and unity for empirically supported values of $\eta_{c}$.

Clearly, a word of caution is in order. In this simulation exercise (reported in Table 4), we assume that households are not positional with respect to wealth, i.e., $\eta_{k}=0$. As is to be learned from Proposition 3, if households are also positional with respect to wealth $\left(\eta_{k}>0\right)$, then the optimal corrective tax- (subsidy-) rates are expected to be lower. In the special case with $\eta_{k}=\eta_{c}$, the optimal corrective tax rates both become equal to zero.

The optimal expenditure share for public capital is affected by both the preference for absolute wealth, $\xi$, as well as the positional preferences, as parameterized by $\left(\eta_{c}, \eta_{k}\right)$. A rise in $\xi$, by raising the marginal utility of consumption, increases the cost of foregone consumption today. Therefore, the higher $\xi$ the more $\hat{g}$ falls short of $(1-\alpha)$. A rise in $\eta_{c}$ has a different impact. It raises the long-run elasticity of intertemporal substitution of $C$, thereby lowering the desire for consumption smoothing. Thus, the fact that the advantage of a larger public investment share materializes only tomorrow whereas the cost in terms of foregone consumption is to be paid today is diminished. As a consequence, the higher is $\eta_{c}$ the higher becomes $\hat{g}$. A parallel argument is valid for wealth positionality.

Two more notes on $\hat{g}$ suggest themselves. First, $\hat{g}$ by itself cannot act as the only optimal policy instrument (replacing either $\hat{\tau}_{c}$ or $\hat{\tau}_{y}$ ). This can easily be verified by comparing the consumption growth rate in the decentralized economy (0) with that in the social optimum (0) 
. The last term in each expression represents the growth rate of private capital. As this growth rate must be equal among the social optimum and the decentralized solution, $g$ must be equal as well. But with $g$ being equal, the first term in each expression (representing the growth rate of consumption) cannot be equal when $\hat{\tau}_{c}=\hat{\tau}_{y}=0$. Second, the optimal endogenous growth rate is quite high. This is (almost) entirely due to the high public infrastructure investment share. In the context of a decentralized economy, we assume a (more realistic) public infrastructure investment share of $g=0.05$ (Chatterjee and Ghosh 2011). In this context, the decentralized endogenous growth rate of per capita consumption amounts to roughly $1.8 \%$ per year. However, as the simulations reveal, the optimal public infrastructure investment share is well above that level of $g=0.05$.

The key lessons from the simulation results are the following. Even if $\eta_{k} \approx \eta_{c}$, the optimal corrective income- and consumption tax rates easily become very large. This seems to contrast the result above, where it was argued that with $\eta_{k} \approx \eta_{c}$, the optimal tax rates are close to zero. That result, however, was true only for $\xi=1$. In contrast, given that $\xi$ differs sufficiently from unity, it is shown that the optimal tax rates can be substantial in spite of $\eta_{k} \approx \eta_{c}$. Moreover, the higher the $\xi$, the more likely the optimal consumption tax is positive, while the optimal income tax is negative. Let $\eta_{k} \approx \eta_{c}$, then in cultures in which people value (absolute) wealth, the optimal consumption tax tends to be positive, while the optimal income tax is negative. Likewise, if $\eta_{k}>\eta_{c}$, the optimal corrective consumption tax rate is negative while the corrective income tax rate is positive. The opposite holds for the case in which $\eta_{k}<\eta_{c}$. In other words, cultures in which people are more positional with respect to wealth (with Protestant ethic, boldly speaking) face structurally different optimal corrective tax schemes from cultures in which people are more positional with respect to consumption.

\section{Conclusion}

This paper contributes to the literature on positional preferences by introducing conspicuous wealth in the agent's utility function, in addition to conspicuous consumption. And it does so within an endogenous growth set-up, both within an AK framework and where the engine of growth is public capital. Production externalities have been captured extensively in much of 
the growth literature, but the same cannot be said about consumption externalities. And even when the latter have been considered, the reference level has mostly been conspicuous consumption rather than wealth. Our paper attempts to plug this gap, given that one objective in foregoing current consumption and accumulating capital, which increases wealth, is that this in itself adds to agents' utility. In the process of enhancing wealth, individual wealth relative to the average is considered as an argument in the utility function. Considerations for absolute and relative wealth both turn out to be important and are captured in detail in our model.

In the paper we found analytically that the presence of wealth positionality always causes distortions (although a preference for absolute wealth by itself is non-distortionary), which are corrected by an optimal consumption- (income-) tax which is negative (positive). We also demonstrate that if wealth is present in the consumer's utility function, then - despite labor supply being inelastic - the introduction of a consumption externality always has a distortionary effect, except when the marginal degree of positionality in wealth exactly matches that of consumption. This modifies the previous results from endogenous growth models where, with inelastic labor supply, such distortionary effects are obtained only with production externalities. Interestingly, in our framework, if wealth is not present in the consumer's utility function, this distortion disappears. In some sense, this result resembles those in models with conspicuous consumption (but not wealth), where there are no distortions; however, such models are typically neoclassical rather than endogenous growth models. While the effects of consumption externalities on growth and welfare in the decentralized economy broadly correspond to those in the social optimum, the effect of wealth externalities is to cause over-accumulation of capital by households in the decentralized economy. Here the social planner, in an effort to correct this externality, picks a growth rate that reduces the rate of capital accumulation to optimal levels. We also conduct some fiscal policy experiments where our results demonstrate that where an increase in public spending occurs, this positively and strongly affects both growth and welfare in the steady state and along the transition path, dominating the impact of consumption externalities.

A number of important policy conclusions emerge from our findings, which are worth emphasizing. First, policymakers should acknowledge the importance of wealth (per se and also conspicuous wealth) in affecting utility, and implement corrective taxation recognizing this aspect of preferences. Second, the simultaneous use of income and consumption 
tax/subsidy instruments as policy tools when preferences are positional is important. Thus, if households are more positional with respect to wealth (consumption), then income (consumption) should be taxed for corrective reasons. Finally, in such models with consumption- and wealth externalities, public spending should be encouraged as it impacts on growth and welfare in a decisive way.

We have performed our analysis in the context of a closed economy, following much of the literature. Our paper could be extended to an open economy context - either a small open economy that has to take the world interest rate as given, or a large economy where economic policies would determine the domestic interest rate as in Ghosh and Mourmouras (2002) where consumption and wealth externalities could be generated not only at home but also abroad. This would add an interesting new dimension to the growth and welfare analysis that we have conducted thus far, and make our analysis richer. To our knowledge, there have not yet been many studies that proceed in this direction: Fisher and Hof (2005) provides an attempt.

Also, the standard growth models typically consider a constant rate of time preference, but recently a "preference-driven theory of economic growth" has been proposed by Strulik (2012), among others, where the rate of impatience varies negatively with wealth, i.e., as wealth increases, individuals tend to become more patient. Given that in our existing set-up, the inclusion of wealth and conspicuous wealth in the utility function makes a significant difference to the workings of the baseline model (where positional preferences are defined with respect to consumption alone), the introduction of wealth-driven time preference will surely introduce another interesting element in the determination of growth and welfare.

Finally, we have in our paper devised appropriate income- and consumption-taxes (under perfect information) to correct distortions. If, instead, we considered agents that were statusconscious but heterogeneous, then one could work out the optimal redistributive taxes for such an economy (see, for example, Mirrlees (1971)). One source of heterogeneity could be the ability level (i.e., the presence of low- and high-ability households), in which case one needs to take into account asymmetric information regarding the ability level. In the context of our model, another source of heterogeneity might be different levels of wealth or different (positional/non-positional) preferences for wealth. 
We have made some progress in pursuing research in these directions, but that would obviously be the subject of other papers and beyond the scope of the current one.

\section{Supplementary material}

Supplementary material - the Appendix - is available online at the OUP website.

\section{Acknowledgements}

We are indebted to Stella Zilian for valuable research assistance. We are most grateful to two anonymous referees (and especially to one of the referees for being so meticulous!), as well as to the associate editor, whose detailed comments and suggestions contributed to substantial improvements of this paper. We also thank Francisco Alvarez-Cuadrado, Thomas Aronsson, John Bennett, Evangelos Dioikitopoulos, Olof Johansson-Stenman, Xavier Raurich, Udayan Roy, Fernando Sanchez, Richard Sturn, Tom Truyts and Ngo Van Long for insightful debates on a previous version of this paper. We are also grateful for helpful feedback during and after presentations at the Indian Statistical Institute in Delhi, as well as at the Universities of Barcelona, Graz, and Luxembourg. We retain sole responsibility for any remaining errors.

\section{References}

Alonso-Carrera, J., J. Caballé, X. Raurich (2005), Growth, Habit Formation, and Catching Up with the Joneses, European Economic Review 49, 1665-1691.

Alpizar, F., F. Carlsson, O. Johansson-Stenman (2005) How Much do we Care About Absolute Versus Relative Income and Consumption?, Journal of Economic Behavior and Organization 56, 405-421.

Alvarez-Cuadrado, F., J.M. Casado, J.M. Labeaga, D. Sutthiphisal (2012), Envy and Habits: Panel Data Estimates of Interdependent Preferences, Banco de Espana Working Paper 1213, available at SSRN: http://ssrn.com/abstract=2014005.

Aronsson, T., Johansson-Stenman, O. (2008), When the Joneses' consumption hurts: optimal public good provision and nonlinear income taxation. Journal of Public Economics 92, 986997.

Aronsson, T., Johansson-Stenman, O. (2010), Positional concerns in an OLG model: optimal labor and capital income taxation. International Economic Review 51, 1071-1095.

Aronsson, T., Johansson-Stenman, O. (2013), Conspicuous leisure: optimal income taxation 
when both relative consumption and relative leisure matter. Scandinavian Journal of Economics 115, 155-175.

Barro, R.J. (1990), Government Spending in a Simple Model of Endogenous Growth, Journal of Political Economy 98, S103-S125.

Baxter, M., R.G. King (1993), Fiscal Policy in General Equilibrium, American Economic Review 83, 315-334.

Blomquist, S. (1993), Interdependent behavior and the effect of taxes. Journal of Public Economics 51, 211-218.

Carroll, C.D., J.R. Overland, D.N. Weil (1997), Comparison Utility in a Growth Model, Journal of Economic Growth 2, 339-367.

Chamley, C. (1986), Optimal Taxation of Capital Income in General Equilibrium with Infinite Lives, Econometrica, 54, 607-622.

Chatterjee, S., S. Ghosh (2011), The Dual Nature of Public Goods and Congestion: The Role of Fiscal Policy Revisited, Canadian Journal of Economics 44, 1471-1496.

Constantinides, G.M. (1990), Habit Formation: A Resolution of the Equity Premium Puzzle, Journal of Political Economy 98, 519-543.

Corneo, G., O. Jeanne (1997), On Relative-Wealth Effects and the Optimality of Growth, Economics Letters 54, 87-92.

Corneo, G., O. Jeanne (2001), On Relative-Wealth Effects and Long-Run Growth, Research in Economics 55, 349-358.

Croushore, D. (1993), Money in the Utility Function: Functional Equivalence to a ShoppingTime Model, Journal of Macroeconomics 15, 175-182.

Dupor, B., W.F. Liu (2003), Jealousy and Equilibrium Overconsumption, American Economic Review 93, 423-428.

Dynan, K. E., and Ravina, E. (2007). "Increasing income inequality, external habits, and selfreported happiness." American Economic Review 97, 226-231.

Easterlin, R.A. (1995), Will Raising the Incomes of All Increase the Happiness of All? Journal of Economic Behaviour and Organisation 27, 35-47.

Eckerstorfer, P., R. Wendner (2013), Asymmetric and Non-atmospheric Consumption Externalities, and Efficient Consumption Taxation, Journal of Public Economics 106, 42-56.

Escobar-Posada, R.A., G. Monteiro (2015), Long-run Growth and Welfare in a Two Sector Endogenous Growth Model with Productive and Non-productive Government Expenditure, Journal of Macroeconomics 46, 218-234.

Fisher, W.H., F.X. Hof (2000), Relative Consumption, Economic Growth, and Taxation, Journal of Economics 72, 241-262. 
Fisher, W.H., F.X. Hof (2005), Status Seeking in the Small Open Economy, Journal of Macroeconomics 27, 209-232.

Frank, R.H. (2005), Positional Externalities Cause Large and Preventative Welfare Distortions, American Economic Review 95, 137-141.

Frank, R.H. (2008), Should public policy respond to positional externalities? Journal of Public Economics 92, 1777-1786.

Futagami, K., Y. Morita, A. Shibata (1993), Dynamic Analysis of an Endogenous Growth Model with Public Capital, Scandinavian Journal of Economics 95, 607-625.

Futagami, K., A. Shibata (1998), Keeping One Step Ahead of the Joneses: Status, the Distribution of Wealth, and Long Run Growth, Journal of Economic Behavior \& Organization 36, 93-111.

Ghosh, S., I.A. Mourmouras (2002), On Public Investment, Long-Run Growth and the Real Exchange Rate, Oxford Economic Papers 54, 72-90.

Gramlich, E.M. (1994), Infrastructure Investment: A Review Essay, Journal of Economic Literature 32, 1176-1196.

Grossman, S., R.J. Shiller (1981), The Determinants of the Variability of Stock Market Prices, American Economic Review 71, 301-307.

Guvenen, F. (2006), Reconciling Conflicting Evidence on the Elasticity of Intertemporal Substitution: A Macroeconomic Perspective, Journal of Monetary Economics 53, 1451-1472.

Hall, R.E. (1988), Intertemporal Substitution in Consumption, Journal of Political Economy 96, 339-357.

Hansen, L.P., K.J. Singleton (1983), Stochastic Consumption, Risk Aversion, and the Temporal Behavior of Asset Returns, Journal of Poltical Economy 91, 249-265.

Hof, F.X., F. Wirl (2008), Wealth Induced Multiple Equilibria in Small Open Economy Versions of the Ramsey Model, Homo Oeconomicus 25, 107-128.

Ireland, N.J. (2001), Optimal income tax in the presence of status effects. Journal of Public Economics 81, 193-212.

Johansson-Stenman, O., F. Carlsson, D. Daruvala (2002), Measuring Future Grandparents' Preferences for Equality and Relative Standing, Economic Journal 112, 362-383.

Judd, K.L. (1985), Redistributive Taxation in a Simple Perfect Foresight Model, Journal of Public Economics, 28, 59-83.

Mankiw, N.G. (1981), The Permanent Income Hypothesis and the Real Interest Rate, Economics Letters 7, 307-311. 
Mankiw, N.G. (1985), Consumer Durables and the Real Interest Rate, Review of Economics and Statistics 67, 353-362.

Layard, R. (2006), Happiness and Public Policy; a challenge to the profession, Economic Journal 116, C24-C23.

Liu, W.F., S.J. Turnovsky (2005), Consumption Externalities, Production Externalities, and Long-Run Macroeconomic Efficiency, Journal of Public Economics 89, 1097-1129.

Lynde, C., J. Richmond (1993), Public Capital and Long-Run Costs in U.K. Manufacturing, Economic Journal 103, 880-893.

Mirrlees, J.A. (1971), An Exploration in the Theory of Optimum Income Taxation, Review of Economic Studies 38, 175-208.

Nakamoto, Y. (2009), Jealousy and Underconsumption in a One-Sector Model with Wealth Preference, Journal of Economic Dynamics and Control 33, 2015-2029.

Oswald, A.J. (1983), Altruism, Jealousy and the Theory of Optimal Non-Linear Taxation, Journal of Public Economics 20, 77-87.

Pham, T.K.C. (2005), Economic Growth and Status-Seeking Through Personal Wealth, European Journal of Political Economy 21, 404-427.

Rae, J. (1905), The Sociological Theory of Capital, New York: Macmillan. (Originally published in 1834.)

Rauscher, M. (1997a), Conspicuous Consumption, Economic Growth, and Taxation, Journal of Economics 66, 35-42.

Rauscher, M. (1997b), Protestant Ethic, Status Seeking, and Economic Growth, ThunenSeries of Applied Economic Theory, No. 09.

Rebelo, S. (1991), Long Run Policy Analysis and Long Run Growth, Journal of Political Economy 99, 500-521.

Romer, P.M. (1986), Increasing Returns and Long-Run Growth, Journal of Political Economy 94, 1002-1037.

Schulte, B. (2014), Overwhelmed Work, Love, and Play when No One has the Time, New York: Sarah Crichton Books.

Smith, A. (1759, 1976), The Theory of Moral Sentiments, in The Theory of Moral Sentiments, Raphael, D.D., A.L. Macfie, eds., Oxford: Oxford University Press.

Solnick, S.J., D. Hemenway (1998), Is More Always Better? A Survey on Positional Concerns, Journal of Economic Behavior \& Organization 37, 373-383.

Solnick, S.J., D. Hemenway (2005), Are Positional Concerns Stronger in Some Domains Than in Others?, American Economic Review 95, 147-151. 
Strulik, H. (2012), Patience and Prosperity, Journal of Economic Theory 147, 336-352.

Tournemaine, F., C. Tsoukis (2008), Relative Consumption, Relative Wealth and Growth, Economics Letters 100, 314-316.

Truyts, T. (2010), Social Status in Economic Theory, Journal of Economic Surveys 24, 137 169.

Turnovsky, S.J. (2004), The Transitional Dynamics of Fiscal Policy: Long-Run Capital Accumulation and Growth, Journal of Money, Credit and Banking, 36, 883-910.

Turnovsky, S.J., G. Monteiro (2007), Consumption Externalities, Production Externalities, and Efficient Capital Accumulation Under Time Non-Separable Preferences, European Economic Review 51, 479-504.

Veblen, T. (1899), The Theory of the Leisure Class, in The Theory of the Leisure Class, republished in 1973, Houghton-Mifflin, Boston, MA.

Weber, M. (1904), The Protestant Ethic and the Spirit of Capitalism, republished in 1958, Charles Scribner's Sons, New York.

Wendner, R. (2014), Ramsey, Pigou, Heterogeneous Agents, and Non-atmospheric Consumption Externalities, Journal of Public Economic Theory 16, 491-521.

Wendner, R., L. Goulder (2008), Status Effects, Public Goods Provision, and the Excess Burden, Journal of Public Economics 92, 1968-1985.

Zou, H. (1994), 'The Spirit of Capitalism' and Long-Run Growth, European Journal of Political Economy 10, 279-293.

Zou, H. (1995), The Spirit of Capitalism and Savings Behavior, Journal of Economic Behavior \& Organization 28, 131-143. 